\title{
UMA INTERFACE ENTRE CULTURA, MOTIVAÇÃO E LUDICIDADE NO ENSINO DE LÍNGUAS
}

\section{Juliana Pessolano Marizete Dalla Corte}

\section{CONSIDERAÇÕES INICIAIS}

As discussões atuais em educação apontam para o estabelecimento de princípios que qualificam o bom ensino ou, pelo menos, garantem um grau razoável de aproximação. Esses princípios fundamentam toda prática educativa, formal ou informal. Embora seja do domínio comum dos educadores o fato de que o início do processo de ensino-aprendizagem deva partir do conhecimento do educando, isto é, de suas experiências, vivências e saberes, as práticas pedagógicas nem sempre se tornam significativas para ele. Eis o ponto conflitante e desafiador do fazer pedagógico: tornar o ensino uma prática relevante e significativa na medida em que haja negociação de sentido. Em outras palavras, queremos que o ensino seja, de fato, uma prática social transformadora.

O problema encontra-se disfarçado na idéia de compromisso assumido em favor de uma educação democrática e libertadora. No entanto, o que acontece é a negação desse comprometimento, evidente nas práticas educativas. A absoluta incoerência contribui para desfazer o ideal de educação que visa promover um sujeito atuante, crítico e autônomo. Para Freire (1999a), a mudança só poderá ocorrer quando se levantar o espírito de rebeldia capaz de abalar o comodismo alienante.

E justamente porque se entende a educação como uma prática comprometida por natureza com a desalienação do homem é que não se pode compreender a permanência de práticas negadoras da história de vida desse sujeito. A superação do paradigma opressor-oprimido implica a participação coletiva dos sujeitos na construção da história da sociedade a partir da reflexão crítica, comprometida com a ação. Este processo é determinado por um contexto histórico e social que exige dos sujeitos o reconhecimento de sua realidade, de seu posicionamento no mundo.

Ajudar a reconhecer-se, a perceber-se como sujeito histórico é dever do educador que também considera a conscientização o caminho para a libertação. A estratégia para conduzir o trabalho de auto-reconhecimento está no exercício de construção e aceitação da identidade cultural do educando. O saber articula-se democraticamente quando se respeita a diversidade local, étnica, social e cultural. Trata-se de um respeito comprometido com o desenvolvimento humano e social, ou melhor, a questão essencial é tornar possível a conscientização dos traços culturais e, ao mesmo tempo, possibilitar a participação dos grupos na (re)construção da própria história. 
É no diálogo que se pode construir um pensar crítico capaz de envolver os sujeitos numa reflexão sobre sua condição no mundo. Cabe lembrar que a educação autêntica não se faz de $A$ para $B$ ou de $A$ sobre $B$, mas de $A \operatorname{com} B$, mediatizados pelo mundo, conforme Freire (1999b: 84). O entendimento dialético sobre a realidade, a situação vivenciada, concreta dos educandos serve como ponto de partida para o desafio de organizar os conteúdos programáticos. A tendência que precisa ser desmitificada é o pensamento de que uma incursão não refletida sobre aspectos da identidade cultural seria o suficiente para formar cidadãos politicamente críticos. Como exemplo de tal pensamento errôneo estaria o ensino associado à cultura.

Ora, se ninguém ensina ninguém, como poderíamos pensar em ensinar cultura de forma autoritária, não diretiva? A cultura não é algo que se possa ensinar porque não existe em si mesma como um conteúdo estático, imutável; pelo contrário, ela é uma prática social e, por essa razão, construída na relação dos homens com o mundo. Como pretender explicar a realidade se não considerarmos 0 conhecimento cultural do educando? Como querer mudar a sociedade se não reconhecermos nas experiências e nas práticas culturais do educando um modo legítimo de ser sujeito-transformador? Uma certeza parece ecoar profundamente: a necessidade de provocar inquietações e desequilíbrios nos estados de plena inconsciência e comodismo.

Entender a cultura como uma prática de natureza social significa considerá-la como um sistema em constante negociação, isto é, um movimento de reinterpretação de informações, conceitos e significados. O desenvolvimento humano, segundo Vygotsky, pressupõe necessariamente a interpretação dos significados culturalmente estabelecidos; por isso é que o contato com os membros do grupo social ou com elementos característicos do ambiente cultural fornece condições para o desenvolvimento psicológico do indivíduo.

\section{MOTIVAÇÃO REFORÇADA, RENDIMENTO PROMISSOR}

Do mesmo modo que se busca aproximar o saber cultural do aluno para estimular o aprendizado e alcançar resultados promissores, é importante que se promova a auto-estima, buscando motivar internamente o educando para a aprendizagem. Segundo Richter (2000: 108), assim como acontece com a auto-estima, é difícil estabelecer se a motivação favorece o aprendizado ou vice-versa ou se ocorre uma circularidade. Parece haver seis componentes que explicam a motivação:

- desejo de explorar o lado desconhecido das experiências e das coisas;

- desejo de manipular o ambiente para modificá-lo;

- desejo de agir física e mentalmente;

- desejo de obter estímulos externos de diversas naturezas;

- desejo de obter conhecimento a partir dos fazeres já mencionados;

- desejo de melhorar a auto-imagem, sendo conhecido e aprovado por outros.

Embora muito usada nos últimos anos no contexto escolar, a palavra motivação 
parece ainda pouco compreendida quando levamos em conta o fato de que a escola perdeu espaço para outros meios ou entidades mais atraentes e motivadoras, ou seja, a escola não motiva nem estimula o interesse e a curiosidade do educando. Isso pode estar acontecendo porque, muitas vezes, não é feita uma distinção entre motivação extrínseca e intrínseca. O aluno motivado extrinsecamente é aquele que persegue um objetivo somente para receber uma recompensa externa, ou seja, o reconhecimento de outros. Por outro lado, o aluno motivado intrinsecamente é aquele que busca o conhecimento para atender suas necessidades e objetivos pessoais (Brown: 1994).

Se a motivação, extrínseca ou intrínseca, é um pressuposto básico para a promoção do bom desempenho em sala de aula, o professor deve estar atento aos elementos geradores desta. Em outras palavras, buscar motivar significa procurar estar próximo ao aluno para descobrir suas necessidades e interesses em relação à aprendizagem. Uma boa iniciativa é investigar junto ao grupo: onde trabalham, onde vivem, se consideram importante aprender línguas, como acham que aprendem melhor, o que esperam aprender, etc.

Essa investigação inicial fornece ao professor noções sobre o contexto sóciocultural e os interesses dos alunos em relação ao que aprender. A partir desse diagnóstico, ao fazer o planejamento de qualquer atividade didática, o professor deve usar a sua sensibilidade para escolher e estabelecer as técnicas a serem utilizadas. Neste momento, deve-se levar em conta as características do grupo (idade, estilos de aprendizagem, interesses, etc.), o eixo temático que pretende desenvolver, as etapas que vai seguir e os objetivos que deseja alcançar.

A aprendizagem de uma língua é como a de qualquer outra matéria, se partirmos da idéia de que este é um processo que ocorre de maneira diferente para cada indivíduo (Gardner: 1983; Paiva: 1999). Assim, não importa se a formação do indivíduo ocorre individualmente, no caso dos autodidatas, ou em aulas particulares ou em grupos orientados por professores. Parece óbvio dizer que a aprendizagem seja um processo singular para cada aluno, basta verificar os dados que comprovam o fracasso escolar.

É possível, portanto, que em uma sala de aula com 15 alunos existam quinze maneiras diferentes de aprendizagem e um único professor com um único sistema de ensino. Se for assim, pode acontecer que o estilo de aprendizagem de algumas pessoas do grupo coincida com a maneira de ensinar do professor, o que as coloca em posição de vantagem em relação aos demais. Cada aluno emprega individualmente estratégias e habilidades diferentes para realizar uma mesma tarefa. Por exemplo, algumas pessoas necessitam primeiro escrever tudo, outras preferem aprender língua falando desde o princípio, enquanto outras precisam de mais recursos de áudio e muitas precisam ainda do apoio da língua materna para conseguirem se firmar na nova língua (Richter: 2000).

Evidentemente, pode acontecer que alguns alunos já tenham tido experiências anteriores, positivas ou negativas. Se positivas, o aluno virá à nossa aula esperando o mesmo método, o mesmo tipo de professor e de aula. Se o que encontrar for muito diferente, poderá se surpreender e ficar receoso porque a 
situação atual não coincide com os esquemas que ele formou sobre aulas de línguas. Se negativa, o aluno pode chegar desestimulado, e também receoso, pois sua experiência anterior não foi boa. Em ambos os casos, o aluno precisa sentir resultados positivos para que se sinta confiante e, conseqüentemente, motivado a participar e a comprometer-se com o aprendizado.

Nossos alunos podem já vir motivados ou não. Nos primeiros dias de aula nos encarregaremos de incrementar ou buscar esta motivação. Existe o perigo de que, passadas as primeiras aulas, comecemos a nos descuidar e esquecer que a motivação se cria de uma maneira contínua e de momento a momento. Acreditamos que a motivação em sala de aula é tarefa de todos. Se somos um grupo de trabalho, devemos repartir responsabilidades. Os alunos devem fazer sugestões, propor temas e atividades, e, se as coisas não vão bem, tentar buscar soluções no próprio grupo.

\section{A LUDICIDADE EM SALA DE AULA: UMA ALTERNATIVA PARA IMPLEMENTAR A MOTIVAÇÃO}

Uma maneira de abordar e estimular a motivação em sala de aula encontra-se no empreendimento lúdico. Os resultados de tal experiência têm otimizado inúmeros fatores positivos para o ensino-aprendizagem: criatividade, desinibição, espontaneidade, socialização, entre outros. Isso se torna um índice a favor da implementação de tarefas lúdicas associadas ao aprendizado justamente porque esses fatores representam algumas condições para o próprio aprendizado.

O lúdico ainda encontra respaldo na perspectiva vygotskyana pela inevitável intervenção na zona de desenvolvimento proximal do educando, ou seja, a interferência de outras pessoas influencia significativamente o desenvolvimento de uma prática individual. A interação com pessoas que possuem diferentes experiências e diferentes níveis de desenvolvimento pode ocorrer informalmente, o que não exclui a legitimidade da aprendizagem, uma vez que esta não é uma simples transmissão de idéias ou práticas, mas a reelaboração individual de conceitos e significados culturalmente difundidos. A aprendizagem, portanto, passa a ser um processo subjetivo de reconstrução individual, amparado pelo princípio de cooperação (Oliveira: 1995).

Numa aula de línguas, jogos podem ser utilizados como suporte, como elemento de apoio, de incentivo, de intercâmbio, de uso da língua, de reestruturação da linguagem. É um bom momento para que o professor faça com que os alunos percam o medo de falar e comprovem seus conhecimentos lingüísticos interiorizados e em condições latentes de emprego.

O professor, ao utilizar algumas técnicas com jogos, consegue com que os alunos fiquem descontraídos e estabelece um ambiente de confiança, além de proporcionar o desenvolvimento de situações dos mais distintos graus e valores, favorecendo a expressão da subjetividade e a construção do conhecimento. Valorizar um jogo no espaço educativo é, pois, fomentar o acesso a novos valores. 
Nesses momentos, o aluno, movido pela descontração, tende a utilizar a língua mais despreocupadamente, possibilitando ao professor detectar dúvidas e avaliar conhecimentos, medindo-os de acordo com os parâmetros exigidos pelo nível em que o aluno se encontra. Ao desenvolver uma atividade com jogos, o professor incentiva, dirige e avalia, porém não interfere diretamente no desenvolvimento da atividade. Suas intervenções serão somente as solicitadas pelo grupo, deixando para o final da atividade as observações que forem pertinentes.

Ainda que a característica intrínseca do elemento lúdico permita a exploração de um ambiente mais light em sala de aula, o seu ponto forte extrapola qualquer visão simplista adotada por defensores de modelos pedagógicos cujos resultados permanecem pouco questionados. Tarefas que focalizam situações imaginárias como o role play, por exemplo, favorecem o desenvolvimento do pensamento abstrato, além de promoverem a circulação de input lingüístico autêntico. As situações, autorizadas por regras sociais capazes de gerar ações questionadoras por parte dos sujeitos envolvidos, tornam-se alvo certo de um bom ensino comunicativo de línguas.

\section{CONSIDERAÇÕES FINAIS}

Embora estejamos contextualizando a possibilidade de uma interface entre cultura, motivação e ludicidade no ensino de línguas, a amplitude e a relevância do tema permitem que sua aplicação seja estendida a outras áreas de ensino. Como uma alternativa teoricamente respaldada, a discussão levantada neste artigo pretende sensibilizar para a produção do conhecimento via interação social nitidamente comprometida com o desenvolvimento legítimo do educando.

No momento em que a capacidade da escola de fornecer condições facilitadoras e estimulantes à aprendizagem encontra-se bastante limitada, o trinômio culturamotivação-ludicidade parece uma fórmula oportuna de resgate da autenticidade do ensino. Uma vez centrado nas experiências e saberes do grupo social ao qual o aluno pertence, o fazer pedagógico encontra perspectivas promissoras para promover um processo socialmente relevante, desde que a intervenção procure atingir a percepção que o indivíduo tem de si mesmo, levando-o à reconstrução crítica dos saberes culturalmente adquiridos. Tal procedimento também apresenta influência direta na auto-estima do professor que procura melhorar a qualidade de suas aulas.

\section{BIBLIOGRAFIA:}

BROWN, H. Douglas. Principles of language learning and teaching. Englewood Cliffs: Prentice Hall Regents, 1994.

FREIRE, Paulo. Pedagogia da autonomia. 13.ed. São Paulo: Paz e Terra, 1999. FREIRE, Paulo. Pedagogia do oprimido. 27.ed. Rio de Janeiro: Paz e Terra, 1999.

GARDNER, Howard. Frames of mind: the theory of multiple intelligences. Basic Books: 1983.

KRAMSCH, Claire. Language and culture. Oxford: Oxford University Press, 1998. 
OLIVEIRA, Marta Kohl de. Vygotsky - aprendizado e desenvolvimento: um processo sócio-histórico. 2.ed. São Paulo: Scipione, 1995.

PAIVA, Maria da Graça Gomes. "Os desafios (?) do ensinar a ler e a escrever em língua estrangeira". In.: NEVES, I.B.; SOUZA, J. V. (Orgs.). Ler e escrever, compromisso de todos. Porto Alegre: Ed. da UFRGS, 1998.

RICHTER, Marcos Gustavo. Ensino do português e interatividade. Santa Maria: Ed. da UFSM, 2000.

VYGOTSKY, L.S. A formação social da mente: o desenvolvimento dos processos psicológicos superiores. 4.ed. São Paulo: Martins Fontes, 1991. 